\title{
Community-acquired methicillin-resistant Staphylococcus aureus infections: 10-years' experience in a children's hospital in the city of Rosario, Argentina
}

\author{
Gabriela Ensinck, M.D. ${ }^{a}$, Adriana Ernst, Biochemist ${ }^{a}$, Gustavo Lazarte, M.D. ${ }^{a}$, \\ Antonela Romagnoli, M.D. ${ }^{a}$, Yanina Sguassero, M.D. ${ }^{b}$, Nanci Míguez, B.S. ${ }^{a}$, \\ Santiago López Papucci, M.D. ${ }^{a}$, Alicia Aletti, M.D. ${ }^{a}$, Ana Chiossone, M.D. ${ }^{a}$, \\ Fernanda Pigozzi, B.S. ${ }^{a}$ and Matías Pinotti, B.S. ${ }^{a}$ \\ Collaborator: Ana Cantador, M.D.c
}

\begin{abstract}
Introduction: Community-acquired methicillinresistant Staphylococcus aureus (CA-MRSA) infections are a common reason for consultation in pediatrics. Most of them present as skin and soft tissue infections; however, invasive infections have increased during the last decade.

Objectives: The main objective was to describe the clinical-epidemiological characteristics of CA-MRSA infections. The secondary objective was to compare prevalence, clinical presentation and antibiotic susceptibility with a pre-study period (1/2004-12/2007).
\end{abstract}

Material and methods: This is a descriptive, prospective, cross-sectional study. Inclusion criteria: children who have been diagnosed with CA-MRSA infection and admitted to Hospital de Niños de Rosario between January 2008 and December 2014. Exclusion criteria: recent hospitalization, previous antibiotic treatment or surgery, comorbidities or immune compromise. Results: Out of 728 cases of children with Staphylococcus aureus infections, $529(73 \%)$ were due to CA-MRSA. The incidence rate of CA-MRSA infections varied from 12.2/10 000 hospital discharges in 2004 to $145 / 10000$ in 2014: $75 \%$ (391) were skin and soft tissue infections; $8 \%$ (43) were osteoarticular infections; $6 \%$ (30), pleuropulmonary infections; 5\% (24), sepsis. There was an increase in the number of invasive infections in the second period, with no statistical significance $(\mathrm{OR}=0.895 ; \mathrm{CI}: 0.52-1.53)$. Gentamicin, clindamycin and erythromycin resistance remained stable throughout both periods.

Conclusion: CA-MRSA infections were increasingly more frequent, mainly skin and soft tissue infections. An increase was observed in the number of invasive infections, with no statistical significance. Antibiotic resistance remained stable.

Key words: Methicillin-resistant Staphylococcus aureus, pediatrics.

http: / / dx.doi.org/10.5546/ aap.2018.eng.119

To cite: Ensinck G, Ernst A, Lazarte G, et al. Community-acquired methicillin-resistant Staphylococcus aureus infections: 10 -years' experience in a children's hospital in the city of Rosario, Argentina. Arch Argent Pediatr 2018;116(2):119-125.

\section{INTRODUCTION}

As of the 1990s, an increase has been observed in community-acquired Staphylococcus aureus (SA) infections worldwide, and this has been mainly due to the community-acquired methicillin-resistant Staphylococcus aureus (CA-MRSA). Although this strain appeared as outbreaks in closed communities at first, it eventually extended and affected the general population. ${ }^{1-3}$

In this context, the acronym "CA-MRSA" refers to infections caused by methicillin-resistant SA andacquired by people living in a community without personal or associated risk factors. CAMRSA strains are phenotypically and genotypically different from strains related to MRSA infections acquired in hospitals or associated to health care, for which reason they are considered to have appeared de novo within the community. They exhibit a staphylococcal cassette chromosome called mec (SCC mec) type IV or V, carry the mecA gene (which makes them resistant to betalactam antibiotics), and can also carry accompanying resistance to other groups of antibiotics. ${ }^{4,5} \mathrm{CA}$ MRSA feature methicillin resistance, variable clindamycin susceptibility and low resistance to trimethoprimsulfamethoxazole. ${ }^{6,7}$

It is worth pointing out that these strains also have genes of PantonValentine leukocidin (PVL), an exotoxin that has been associated with invasiveness, necrosis and poor prognosis. ${ }^{8,9}$ 
At present, CA-MRSA infections are a common reason for consultation in pediatrics and, in most cases, they develop as skin and soft tissue infections (SSTIs). ${ }^{10}$ In the past ten years, invasive infections such as bacteremia, osteoarthritis and pleuropulmonary suppuration have increased among children. ${ }^{1,2,11}$ CA-MRSA infections are also characterized by their risk of recurrence and ability to cause secondary focus of infection. ${ }^{12}$

The first reports of CA-MRSA infections in South America appeared in 2003, ${ }^{13}$ and, in 2004, Paganini et al. ${ }^{14}$ published the first report about this type of infections in children in Argentina. Considering its high prevalence, it is essential to know the local epidemiological situation in order to set the criteria regarding therapeutic approaches.

The main objective of this study was to describe the clinical-epidemiological characteristics of CA-MRSA infections. The secondary objective was to compare prevalence, clinical presentation and antibiotic susceptibility with a pre-study period (1/2004-12/2007).

\section{POPULATION AND METHODS}

A descriptive, prospective, cross-sectional study was carried out in children and adolescents with documented diagnosis of CA-MRSA infection seen at Hospital de Niños Víctor J. Vilela, Rosario city, from January 2008 to December 2014. This study was compared to a previous prospective, descriptive study that had been carried out in our hospital between January 2004 and December 2007.

The same clinical diagnostic, inclusion and exclusion criteria were used in both periods, as well as the same microbiological methodology.

Exclusion criteria were patients who had been hospitalized (for at least 24 hours), had visited a health care center or had been in contact with health care staff within six months prior to study enrollment; patients who had received antibiotics or had a previous history of MRSA isolation; patients who had had a catheter for a long time or had undergone hemodialysis or a surgical procedure. Furthermore, patients with comorbidities at the time of enrollment, such as immunosuppression, diabetes, corticosteroid therapy, etc., were excluded. Patients who lacked data regarding the outcome measures analyzed were not excluded, but this was pointed out in each case.

The infection was considered "community acquired" when at least one culture positive for
SA was taken from an outpatient or within the first 48 hours of hospitalization.

As regards microbiological diagnosis, the sample for the culture was taken by punctureaspiration, or drainage of the skin and soft tissue lesion or sterile sites. SA was isolated and typified by means of conventional, automated microbiological testing, as per working protocols established by the hospital's Microbiology Laboratory.

Susceptibility to methicillin was determined using the disk diffusion method with a $30 \mu \mathrm{g}$ cefoxitin disk. Resistance was defined as the presence of halos smaller than $20 \mathrm{~mm}$. Resistance to rifampicin $(5 \mu \mathrm{g})$, gentamicin $(10 \mu \mathrm{g})$, trimethoprim-sulfamethoxazole $(25 \mu \mathrm{g})$, erythromycin $(15 \mu \mathrm{g})$ and clindamycin $(2 \mu \mathrm{g})$ was also determined. Antibiograms were interpreted according to currently valid guidelines of the Clinical and Laboratory Standards Institute (CLSI, 2014). ${ }^{15}$ Inducible clindamycin resistance was identified placing the disk at a distance of $25 \mathrm{~mm}$ from erythromycin disk in the antibiogram (D-test). Vancomycin minimum inhibitory concentration (MIC) was established by microdilution or using the agar dilution method with E-test strips.

A $\log$ was designed to record the following data: sex, age, clinical manifestations, location of lesions and antibiotic susceptibility of the isolated microorganism.

Data analysis was performed globally. For the statistical analyses, SAS 9.2 software was used. Categorical outcome measures were expressed as number and percentage. Odds ratio (OR) and 95\% confidence interval (CI) were also calculated for primary outcomes. Continuous outcome measures were expressed as median and range. Study group comparisons were done using Student's t-test. The statistical significance level was established at $\alpha=0.05$.

The research protocol was endorsed by the Ethics Committee of the Secretary of Public Health of the Municipality of Rosario, and approved by the Teaching and Research Committee of Hospital de Niños Víctor J. Vilela. Before enrolling a child in the study, a member of the research staff informed the parents or guardian about its objectives and descriptive nature, and made it clear that participating in the study would not affect the conduct of care or the treatment received by the child. The research team guaranteed anonymity and information confidentiality. 


\section{RESULTS}

During the study period (2004-2014), 728 children with a diagnosis of SA infection were identified, among which $529(73 \%)$ were infected with CA-MRSA (Figure 1). Within this setting, it was observed that the incidence rate of CA-MRSA infections increased from 12.2/10 000 hospital discharges in 2004 (first year of the first period) to 145/10 000 in 2014 (last year of the second period), which implies a twelvefold increase between the first and the last year of the study period. Clinical and epidemiological characteristics were studied in a sample of 456 children with 520 CA-MRSA infections (one child had more than one infection site), who were seen between 2008 and 2014. Of these children, $57.6 \%(n=263)$ were males, and median age was 60 months (1-202). The general characteristics of the sample are presented in Table 1.

Among the 520 clinical presentations, the most common ones were: SSTIs $(75 \%, n=391)$, which included cellulitis, cellulitis with abscess, impetigo and myositis; osteoarticular infections $(8 \%, \mathrm{n}=43)$; pleuropulmonary infections $(6 \%$,

FigURE 1. Number of patients with community-acquired methicillin-resistant Staphylococcus aureus infection per year. 2004-2014 period, Hospital de Niños Víctor J. Vilela, Rosario

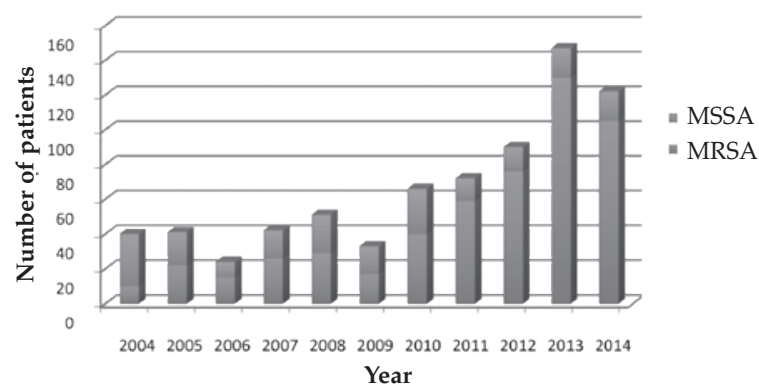

MSSA: Methicillin-susceptible Staphylococcus aureus. MRSA: Methicillin-resistant Staphylococcus aureus.

TABLE 1. Clinical and epidemiological characteristics of children with community-acquired methicillin-resistant Staphylococcus aureus infection $(n=456)$. 2008-2014 period, Hospital de NiñosVíctor J. Vilela, Rosario

\begin{tabular}{|c|c|c|}
\hline Outcome measures & Number & Percentage $(\%)$ \\
\hline Boys & 263 & 57.6 \\
\hline $\begin{array}{l}\text { Age group } \\
<12 \text { months old } \\
12-60 \text { months old } \\
>60 \text { months old }\end{array}$ & $\begin{array}{c}48 \\
253 \\
155\end{array}$ & $\begin{array}{c}10.52 \\
55.48 \\
34\end{array}$ \\
\hline $\begin{array}{l}\text { Clinical manifestation }{ }^{* *} \\
\text { SSTI } \\
\text { Pleuropulmonary infections } \\
\text { Osteoarticular infections } \\
\text { Sepsis } \\
\text { Other }\end{array}$ & $\begin{array}{c}391 \\
30 \\
43 \\
24 \\
46\end{array}$ & $\begin{array}{l}75 \\
6 \\
8 \\
5 \\
6\end{array}$ \\
\hline $\begin{array}{l}\text { Location of lesions } \\
\text { Lower limbs and buttocks } \\
\text { Chest } \\
\text { Upper limbs } \\
\text { Head and neck } \\
\text { Other }\end{array}$ & $\begin{array}{c}228 \\
62 \\
45 \\
42 \\
15\end{array}$ & $\begin{array}{c}58 \\
16 \\
11 \\
11 \\
4\end{array}$ \\
\hline $\begin{array}{l}\text { Antibiotic susceptibility } \\
\text { Oxacillin } \\
\text { Erythromycin } \\
\text { Clindamycin } \\
\text { Gentamicin }\end{array}$ & $\begin{array}{c}366 \\
38 \\
30 \\
25\end{array}$ & $\begin{array}{c}0 \\
85 \\
9 \\
7 \\
6\end{array}$ \\
\hline $\begin{array}{l}\text { Microbiological isolation } \\
\text { SSTI* } \\
\text { Blood cultures } \\
\text { Pleural fluid } \\
\text { Joint fluid } \\
\text { Bone puncture and deep abscesses } \\
\text { Pericardial fluid }\end{array}$ & $\begin{array}{c}390 \\
37 \\
25 \\
24 \\
5 \\
2\end{array}$ & $\begin{array}{c}80 \\
8 \\
5 \\
5 \\
1 \\
0.4\end{array}$ \\
\hline
\end{tabular}

* Some children exhibited more than one type of clinical presentation. SSTI: skin and soft tissue infection 
$\mathrm{n}=30)$, and sepsis $(5 \%, \mathrm{n}=24)$. It should be noted that 40 children $(8.7 \%)$ presented two or more sources of infection. In 377 cases $(72.5 \%)$, surgical drainage was required as part of treatment. One hundred and twenty five (24\%) invasive infections and two deaths were recorded. Infection sites were studied in $392(86 \%)$ of the 456 children, of which $33(8 \%)$ presented more than one site of infection. Most common sites were lower limbs and buttocks $(58 \%, \mathrm{n}=228)$, followed by chest $(16 \%, \mathrm{n}=62)$, upper limbs $(11 \%, \mathrm{n}=45)$, head and neck $(11 \%, \mathrm{n}=42)$, deep abscesses $(1 \%, \mathrm{n}=3)$ and bacteremia without source $(0.5 \%, \mathrm{n}=2)$.

CA-MRSA was isolated from 488 samples: SSTI cultures $(80 \%, \mathrm{n}=390)$, blood cultures $(8 \%, \mathrm{n}=37)$, pleural fluid $(5 \%, \mathrm{n}=25)$, joint fluid $(5 \%, \mathrm{n}=24)$, bone marrow aspiration $(1 \%, \mathrm{n}=5)$, pericardial fluid $(0.43 \%, \mathrm{n}=2)$ and punctureaspiration of deep abscesses in two cases. In 25 children (5\%), CA-MRSA was isolated in more than one sample (Table 2). Antibiotic susceptibility pattern was studied for all 488 isolates (there was more than one isolate per patient) and oxacillin exclusive resistance was observed in $419(86 \%)$ of them. Furthermore, accompanying resistance to erythromycin was observed in 44 strains (9\%), to clindamycin in $34(7 \%)$ and to gentamicin in $29(6 \%)$. The most frequent combination was resistance to erythromycin plus clindamycin. No resistance to trimethoprimsulfamethoxazol, rifampicin or ciprofloxacin was observed. Vancomycin susceptibility was studied in 376 isolates: MIC was $\leq 1 \mathrm{ug} / \mathrm{ml}$ in $359(95.47 \%)$ of them and $1.5 \mathrm{ug} / \mathrm{ml}$ in the remaining $17(4.53 \%)$. No strain had a MIC $\geq 2$.

An increase in osteoarticular and pleuropulmonary infections was observed during the second period; however, the risk of developing invasive infections was not higher than in the first period. Invasive infections:
$111 / 520$ versus $15 / 78, \mathrm{OR}=1.1399$ (CI: $0.6250-$ 2.0788), $\mathrm{p}=0.6694$ (Table 3).

In terms of antibiotic resistance to gentamicin, clindamycin, and erythromycin, the differences between the first and second periods were not statistically significant (Table 4). In neither period was resistance to trimethoprim-sulfamethoxazol, rifampicin or ciprofloxacin observed.

\section{DISCUSSION}

The increase in CA-MRSA infections, specially SSTIs, has resulted in a three or fourfold increase in medical consultation. ${ }^{16}$ An extensive study carried out in children's hospitals in Argentina in 2007 reflects the growing number of cases in hospitalized children and revealed a $61 \%$ rate of methicillin resistance in the strains studied. ${ }^{17}$ Other relevant studies performed in Argentina between 2012 and 2014 describe the circulating clones among pediatric population, the most common being ST5-IV-PVL+, with a methicillin resistance rate of around 55\%.18,19 Our 10 years' experience showed a threefold increase of infections caused by CA-SA, approximately, with an average of $73 \%$ of infections being caused by CA-MRSA, as well as a twelvefold increase in the rate of CA-MRSA infections per hospital discharges from the first year of the study to the last (2004-2014).

Mean age of our patients was around 5 years, yet, more than half of them were younger than 4 years old, which is consistent with other national publications. ${ }^{14,20,21}$ There was no sex prevalence in this study, unlike in other series, in which a male prevalence was clearly observed and the fact that boys were more frequently affected was presented as background information. ${ }^{20}$

Of all infections, SSTI was the most frequent clinical presentation. Among SSTIs, cellulitis with abscess was the most common presentation,

TABLE 2. Isolation site of community-acquired methicillin-resistant Staphylococcus aureus infections. 2008-2014 period, Hospital de NiñosVictor J. Vilela, Rosario

\begin{tabular}{lcc}
\hline CA-MRSA isolation & Number & Percentage \\
\hline SST & 390 & 80.00 \\
Blood culture & 37 & 8.11 \\
Pleural fluid & 25 & 5.48 \\
Joint fluid & 24 & 5.26 \\
Bone marrow aspiration & 5 & 1.10 \\
Abscess puncture-aspiration & 2 & 0.44 \\
Pericardial fluid & 2 & 0.44 \\
Other & 3 & 0.66 \\
Total & 488 & 100.00 \\
\hline
\end{tabular}

CA-MRSA: community-acquired methicillin-resistant Staphylococcus aureus; SST: skin and soft tissue. 
followed by cellulitis without abscess, impetigo, folliculitis and myositis. Both myositis and fascitis are serious types of infection that often require invasive treatments. ${ }^{17,22}$ The authors sustain that there is a correlation between these lesions and a SA virulence factor known as PVL. This is a cytotoxin that causes leukocyte destruction and tissue necrosis, thus favoring the microorganism capacity to form abscesses. A published metaanalysis supports the relationship between PVL and skin and soft tissue lesions, and disregards the association of PVL with invasive infections..$^{23,24}$

The second most frequent clinical presentation were osteoarticular infections, which was consistent with the results obtained by other authors. ${ }^{25}$ In general, thrombophlebitis was part of the myositis-arthritis and osteomyelitis complex. Pleuropulmonary infections were in the third place, mainly as necrotizing pneumonias and pleuropulmonary suppurations. An increase of pneumonia cases caused by MRSA in children, mainly in the form of empyemas, has been described worldwide. ${ }^{26,28}$

During an experience carried out at our hospital (not yet published), pleuropulmonary infections presented as empyemas in $100 \%$ of the cases, and $50 \%$ of them exhibited necrosis and abscesses. Fifty percent of pleuropulmonary conditions were accompanied by sepsis. ${ }^{29}$

Two of the cases of sepsis developed as sepsis without source, with skin lesions similar to meningococcal disease, and only these two patients died during the second period of the study. This low fatality rate of $<1 \%$ is similar to that published by other authors. ${ }^{17,22}$ The other presentations, such as adenitis, endocarditis, pericarditis, etc., were much less frequent.

In $75 \%$ of the cases, isolates were obtained from SSTIs; $8 \%$ were isolated from blood cultures, a similar percentage to that reported by other health centers in our country, ${ }^{21}$ followed by pleural and joint fluid.

Eighty percent of the strains were only resistant to oxacillin, with an accompanying resistance lower than $10 \%$ for erythromycin, clindamycin and gentamicin. No resistance to trimethoprimsulfamethoxazol, rifampicin or ciprofloxacin was observed. Inducible clindamycin resistance was studied in erythromycin-resistant strains using D-test. A resistance rate lower than $15 \%$ make

TABLE 3. Clinical presentations of community-acquired methicillin-resistant Staphylococcus aureus infections. 2004-2007 and 2008-2014 periods, Hospital de NiñosVíctor J. Vilela, Rosario

\begin{tabular}{|c|c|c|c|}
\hline \multirow[b]{2}{*}{ SSTI } & \multirow{2}{*}{$\begin{array}{c}2004-2007 \\
78 \text { infections/73 patients } \\
59(75.6 \%)\end{array}$} & \multicolumn{2}{|c|}{$\begin{array}{c}2008-2014 \\
520 \text { infections/456 patients }\end{array}$} \\
\hline & & $391(75 \%)$ & NS (p: 0.6879) \\
\hline Osteoarticular & $4(5 \%)$ & $43(8 \%)$ & NS (p: 0.3413) \\
\hline PPS/NP & $1(1.2 \%)$ & $30(6 \%)$ & NS (p: 0.1299) \\
\hline Sepsis & $4(5.12 \%)$ & $24(4.61 \%)$ & NS (p: 0.8416) \\
\hline Adenitis & $4(5.12 \%)$ & $18(3.46 \%)$ & NS (p: 0.4688) \\
\hline Deep abscesses & $2(2.5 \%)$ & $3(0.57 \%)$ & NS (p: 0.1090) \\
\hline Thrombophlebitis & $1(1.2 \%)$ & $3(0.57)$ & NS (p: 0.5071) \\
\hline Pericarditis & $1(1.2 \%)$ & $3(0.57)$ & NS (p: 0.5071) \\
\hline Endocarditis & $1(1.2 \%)$ & $2(0.38 \%)$ & NS (p: 0.3387) \\
\hline Peritonitis & $0(0 \%)$ & $2(0.38 \%)$ & NS \\
\hline Mediastinitis & $1(1.2 \%)$ & $1(0.2 \%)$ & NS (p: 0.1871) \\
\hline
\end{tabular}

SSTI: skin and soft tissue infection; PPS/NP: pleuropulmonary suppurations / nosocomial pneumonia; NS: not significant. Invasive infections: $111 / 520$ versus $15 / 78, \mathrm{OR}=1.1399$ (CI: 0.6250-2.0788), $\mathrm{p}=0.6694$.

TABLE 4. Types of accompanying resistance to oxacillin in community-acquired methicillin-resistant Staphylococcus aureus infections. 2004-2007 and 2008-2014 periods, Hospital de Niños Víctor J. Vilela, Rosario

\begin{tabular}{|c|c|c|c|c|}
\hline \multirow[b]{2}{*}{ Antibiogram } & \multicolumn{4}{|c|}{ Accompanying resistance to oxacillin in both periods } \\
\hline & 2004-2007 (78)* & $2008-2014(488)^{*}$ & OR & \\
\hline Gentamicin & 3.2 & 5.6 & $\mathrm{OR}=1.97$ & $C I=(0.46 ; 8.53)$ \\
\hline Clindamycin & 6.5 & 7.2 & $\mathrm{OR}=1.26$ & $\mathrm{CI}=(0.43 ; 3.68)$ \\
\hline Erythromycin & 6.5 & 9.3 & $\mathrm{OR}=1.66$ & $\mathrm{CI}=(0.58 ; 4.78)$ \\
\hline
\end{tabular}

* Analyzed microorganisms.

OR: odds ratio; CI: confidence interval. 
it possible for these antibiotics to be part of our Hospital's therapeutic armory. ${ }^{30,31}$ Vancomycin MIC was $\leq 1$ in $95 \%$ of the strains, and no strain had a MIC $\geq 2$; which is therapeutically relevant, since vancomycin is the drug of choice for the treatment of bacteremic severe forms of this infection in pediatrics. ${ }^{32}$

Two thirds of the patients required surgery. Undoubtedly, due to the microorganism capacity to cause abscesses and necrosis, collections drainage is essential when treating these infections. ${ }^{33}$

When comparing both study periods, a higher number and a greater variety of invasive infections, mainly osteoarticular and pulmonary infections, can be observed in the second period. However, the risk of developing invasive infections was not statistically relevant in neither periods. ${ }^{11}$

The antibiotic resistance pattern remained stable throughout both periods. Accompanying resistance percentages were similar to those published by other authors in our country. ${ }^{17,21}$

One of the limitations of our study was that it was conducted in a single center and that, despite being a prospective study, some data were not consistently recorded in the first and second periods. SSTI rate may be limited by the fact that not all skin lesions were microbiologically analyzed. Since the number of deaths is low, it is not possible to assess the impact of this infection on mortality. It should also be pointed out that our patients were healthy children, with no previous conditions.

Definitely, the study's strength is the number of patients and the 10-year-period of study, which allowed us to assess the increase in the number of infections, the increase in methicillin resistance, and the stability of accompanying antibiotic resistance.

To conclude, CA-SA infections have increased in recent years, to the expense of CA-MRSA. The most common clinical presentations were SSTIs, in the form of cellulitis with abscess. Ostearticular and pulmonary invasive forms were predominant and, even if they were more in quantity during the second period, no increase in invasiveness was observed in comparison to the first period. Accompanying antibiotic resistance remained stable over time, below $15 \%$, which allowed the use of such antibiotics for initial empirical treatments, based on the clinical presentation.

The rapid implementation of the appropriate medical treatment and surgical drainage in the cases mentioned will undoubtedly have an impact on these patients' morbidity and mortality.

\section{REFERENCES}

1. Buckingham SC, McDougal LK, Cathey LD, et al. Emergence of community-associated methicillin-resistant Staphylococcus aureus at a Memphis, Tennessee Children's Hospital. Pediatr Infect Dis J 2004;23(7):619-24.

2. Miller LG, Kaplan SL. Staphylococcus aureus: A Community Pathogen. Infect Dis Clin North Am 2009;23(1):35-52.

3. Kirkland EB,Adams BB. Methicillin-resistant Staphylococcus aureus and athletes. J Am Acad Dermatol 2008;59(3):494-502.

4. Berglund C, Söderquist B. The origin of a methicillinresistant Staphylococcus aureus isolate at a neonatal ward in Sweden - Possible horizontal transfer of a staphylococcal cassette chromosome mec between methicillin-resistant Staphylococcus haemolyticus and Staphylococcus aureus. Clin Microbiol Infect 2008;14(11):1048-56.

5. International Working Group on the Classification of Staphylococcal Cassette Chromosome Elements (IWGSCC). Classification of staphylococcal cassette chromosome mec (SCCmec): Guidelines for reporting novel SCCmec elements. Antimicrob Agents Chemother 2009;53(12):4961-7.

6. Paganini H, DellaLatta M, Muller B, et al. Estudio multicéntrico sobre las infecciones pediátricas por Staphylococcus aureusmeticilino-resistente provenientes de la comunidad en la Argentina. Arch Argent Pediatr 2008;106(5):397-403.

7. Frei CR, Miller ML, Lewis JS, et al. Trimethoprimsulfamethoxazole or clindamycin for communityassociated MRSA (CA-MRSA) skin infections. J Am Board Fam Med 2010;23(6):714-9.

8. Adler A, Temper V, Block CS, et al. Panton-Valentine leukocidin-producing Staphylococcus aureus. Emerg Infect Dis 2006;12(11):1789-90.

9. Morgan MS. Diagnosis and treatment of Panton-Valentine leukocidin (PVL)-associated staphylococcal pneumonia. Int J Antimicrob Agents 2007;30(4):289-96.

10. Committee on Infectious Diseases of the Argentine Society of Pediatrics. Infecciones de piel y partes blandas en pediatría: consenso sobre diagnóstico y tratamiento. Arch Argent Pediatr 2014;112(1):96-102.

11. Boucher H, Miller LG, Razonable RR. Serious Infections Caused by Methicillin. Resistant Staphylococcus aureus. Clin Infect Dis 2010;51(Suppl 2):S183-97.

12. Elston DM. Community-acquired methicillin-resistant Staphylococcus aureus. J Am Acad Dermatol 2007;56(1):1- 16.

13. Galiana Villar A. Infección por Staphylococcus aureus meticilino resistente adquirido en la comunidad. Arch Pediatr Urug 2003;74(1):26-9.

14. PaganiniDH, Verdaguer V, Rodríguez AC, et al. Infecciones causadas por Staphylococcus aureus resistentes a la meticilina en niños provenientes de la comunidad en niños de la Argentina. Arch Argent Pediatr 2006;104(4):295-300.

15. Rapoport M. Novedades 2014. Clinical and Laboratory Standards Institute (CLSI). 2014:187-192. [Accessed on: September13rd,2017].Availableat:http: / / antimicrobianos. com.ar / ATB / wp-content/uploads / 2014/06/ NOVEDADES-CLSI-2014v21.pdf.

16. Wallin TR, Hern HG, Frazee BW. Community-Associated Methicillin-Resistant Staphylococcus aureus. Emerg Med Clin North Am 2008;26(2):431-55.

17. Paganini MH, Della L. P, Muller OB, et al. Infecciones por Staphylococcus aureus resistente a meticilina adquiridas en la comunidad en niños antes sanos y en niños relacionados al hospital en la Argentina. Rev Chil Infectol 2009;26(5):40612. 
18. Egea AL, Gagetti P, Lamberghini R, et al. New patterns of methicillin-resistant Staphylococcus aureus (MRSA) clones, community-associated MRSA genotypes behave like healthcare-associated MRSA genotypes within hospitals, Argentina. Int J Med Microbiol 2014;304(8):1086-99.

19. Sola C, Paganini $H$, Egea $A L$, et al. Spread of epidemic MRSA-ST5-IV clone encoding PVL as a major cause of community onset staphylococcal infections in Argentinean children. PLoS One 2012;7(1):e30487.

20. Ves Losada JE, Graziano AP, De Abreu M, et al. Infecciones graves por Staphylococcus aureus: características clínicas, sensibilidad antibiótica y uso de antimicrobianos. Serie de casos. Arch Argent Pediatr 2014;112(4):e152-5.

21. Pérez G, Martiren S, Reijtman V, et al. Bacteriemia por Staphylococcus aureus adquirido en la comunidad en niños: estudio de cohorte 2010-2014. Arch Argent Pediatr 2016;114(6):508-513.

22. Kaplan SL. Community-Acquired Methicillin-Resistant Staphylococcus aureus Infections in Children. Semin Pediatr Infect Dis 2006;17(3):113-9.

23. Tristan A, Bes M, Meugnier $H$, et al. Global distribution of Panton-Valentine leukocidin-positive methicillin-resistant Staphylococcus aureus, 2006. Emerg Infect Dis 2007;13(4):594600.

24. Rouzic N, Janvier F, Libert N, et al. Prompt and successful toxin-targeting treatment of three patients with necrotizing pneumonia due to Staphylococcus aureus strains carrying the panton-valentine leukocidin genes. J Clin Microbiol 2010;48(5):1952-5.

25. Kaplan SL. Osteomyelitis in children. Infect Dis Clin North Am 2005;19(4):787-97.

26. Sicot N, Khanafer N, Meyssonnier V, et al. Methicillin resistance is not a predictor of severity in communityacquired Staphylococcus aureus necrotizing pneumoniaresults of a prospective observational study. Clin Microbiol Infect 2012;19(3):e142-8.

27. Li HT, Zhang TT, Huang J, et al. Factors associated with the outcome of life-threatening necrotizing pneumonia due to community-acquired Staphylococcus aureus in adult and adolescent patients. Respiration 2011;81(6):448-60.

28. Carrillo-marquez MA, Hulten KG, Hammerman W, et al. Staphylococcus aureus Pneumonia in Children in the Era of community-acquired methicillin-resistence at Texas Children`s Hospital. Pedriatr infect Dis J 2011;30(7):545-50.

29. Ensinck G, Lazarte G, Ernst A, et al. Community-Acquired Methicillin Resistant Staphylococcus aureus (CA-MRSA) Pneumonia in a Children' s Hospital - Our experience. Study presented as a poster at the 34th Annual Meeting of the European Society for Pediatric Infectious Diseases; May 10-14, 2016; Brighton, UK. ESP16-1086. [Accessed on: September 14th, 2017]. Available at: https://www. collectlane.com/\#/post-event/26/posters/13198.

30. Chuck EA, Frazee BW, Lambert L, et al. The Benefit of Empiric Treatment for Methicillin-Resistant Staphylococcus Aureus. J Emerg Med 2010;38(5):567-71.

31. Messina AF, Namtu K, Guild M, et al. Trimethoprimsulfamethoxazole Therapy for Children With Acute Osteomyelitis. Pediatr Infect Dis J 2011;30(12):1019-21.

32. Hoang J, Dersch-Mills D, Bresee L, et al. Achieving Therapeutic Vancomycin Levels in Pediatric Patients. Can J Hosp Pharm 2014;67(6):416-22.

33. FergieJ, Purcell K. The Treatment of Community-Acquired Methicillin-Resistant Staphylococcus aureus Infections. Pediatr Infect Dis J 2008;27(1):67-8. 